\title{
Lithium induced reversible Splenial lesion in neuroleptic malignant syndrome like symptoms: two case reports
}

\author{
Han Uk Ryu ${ }^{1 \dagger}$, Ji Yeon Chung ${ }^{2 \dagger}$, Byoung-Soo Shin ${ }^{3}$ and Hyun Goo Kang ${ }^{3^{*}}$ (D)
}

\begin{abstract}
Background: Lithium is primarily used to treat bipolar disorder and is known to cause several acute neurological complications. Reversible splenial lesions (RSLs) may be evident in antiepileptic drug toxicity or withdrawal, infections, and other phenomena. We report two cases of RSL presenting as neuroleptic malignant syndrome-like symptoms (NMSLS) with lithium associated neurotoxicity.
\end{abstract}

Case presentation: A 28-year-old woman was admitted after taking increased dosages of lithium for schizophrenia. She experienced generalized tremor, rigidity, dysarthria, high fever, and tachycardia. Symptoms and brain lesion recovered 2 weeks after discontinuation of lithium. The second case involved a 59-year-old woman who was receiving treatment for bipolar disorder since 1988. When lithium was administered for impatience and aggressive behavior, her mental state deteriorated and fever developed, along with generalized tremor in the extremities. Brain magnetic resonance imaging (MRI) in both patients showed a reversible oval-shaped lesion localized to the splenium of the corpus callosum. Both patients were defined as neuroleptic malignant syndrome-like symptoms (NMSLS) based on the DSM-5 diagnostic criteria for neuroleptic malignant syndrome. The suspected etiology of our cases was lithium associated neurotoxicity according to their clinical course and medical information. Our patients fully recovered in 10-14 days after the discontinuation of lithium.

Conclusions: The patients experienced similar clinical courses and had similar radiological findings of RSL. Manifestations in both cases were related to lithium associated neurotoxicity and this should be considered in patients with RSL and NMSLS.

Keywords: Lithium, Neuroleptic malignant syndrome, Reversible splenial lesion

\section{Background}

Lithium is often used as a treatment of choice for patients with bipolar disorders [1]. Despite its utility in psychiatric treatment, lithium has a narrow therapeutic range, which may easily lead to unexpected neurological

\footnotetext{
* Correspondence: hgkang@jbnu.ac.kr

${ }^{\dagger}$ Han Uk Ryu and Ji Yeon Chung contributed equally to this work.

${ }^{3}$ Department of Neurology, Research Institute of Clinical Medicine of Jeonbuk National University - Biomedical Research Institute of Jeonbuk National University Hospital, Deokjin-gu, Jeonju-si, Jeonbuk-do 54907, South Korea

Full list of author information is available at the end of the article
}

complications such as encephalitis, convulsion, tremor, gait ataxia, altered mental state, and neuroleptic malignant syndrome-like symptoms (NMSLS) [2]. Reversible splenial lesion (RSL) of the corpus callosum has been reported to be a nonspecific finding associated with clinical symptoms of mild encephalitis or encephalopathy. Several etiologies, including antiepileptic medication, alcohol abuse, hypoglycemia, infection, electrolyte imbalance, and trauma are related to the development of RSL [3]. Although RSL has various causes, an association with psychiatric drugs, such as lithium, has not been

(c) The Author(s). 2020 Open Access This article is licensed under a Creative Commons Attribution 4.0 International License, which permits use, sharing, adaptation, distribution and reproduction in any medium or format, as long as you give appropriate credit to the original author(s) and the source, provide a link to the Creative Commons licence, and indicate if changes were made. The images or other third party material in this article are included in the article's Creative Commons licence, unless indicated otherwise in a credit line to the material. If material is not included in the article's Creative Commons licence and your intended use is not permitted by statutory regulation or exceeds the permitted use, you will need to obtain permission directly from the copyright holder. To view a copy of this licence, visit http://creativecommons.org/licenses/by/4.0/ The Creative Commons Public Domain Dedication waiver (http://creativecommons.org/publicdomain/zero/1.0/) applies to the data made available in this article, unless otherwise stated in a credit line to the data. 
proven. We encountered two patients with RSL and NMSLS who had taken lithium for bipolar disorder.

\section{Case presentation}

\section{Case 1}

A 28-year-old woman, who had schizophrenia since 2014, was referred to the emergency department in an altered mental state. She had been taking lithium at $1200 \mathrm{mg} /$ day for 4 years: quetiapine at $400 \mathrm{mg} /$ day, clonazepam at $0.5 \mathrm{mg} /$ day, and risperidone at $5 \mathrm{mg} /$ day for several months (Fig. 1). The lithium dosage was increased to $1800 \mathrm{mg} /$ day, 12 days before admission, due to her disoriented speech and aggressive behavior. The patient was referred to our hospital after 2 days of generalized tremor, rigidity, dysarthria, high fever $\left(38^{\circ} \mathrm{C}\right)$, and tachycardia (120 beats/min). Vital signs at admission included blood pressure at $130 / 100 \mathrm{mmHg}$, heart rate at 104 beats $/ \mathrm{min}$, and body temperature at $37.2{ }^{\circ} \mathrm{C}$. Her lithium level was $1.24 \mathrm{mmol} / \mathrm{L}$, slightly higher than the upper normal limit $(0.5-1.0 \mathrm{mmol} / \mathrm{L})$. The patient was diagnosed with NMSLS, and all medications, including lithium, were discontinued. Brain magnetic resonance imaging (MRI) revealed an oval-shaped, high signal intensity lesion on diffusion-weighted imaging (DWI) with decreased apparent diffusion coefficient (ADC) values localized to the splenium of the corpus callosum (Fig. 2a). The patient fully recovered in 2 weeks and experienced no relapses after further treatment with quetiapine, clonazepam, and risperidone.

\section{Case 2}

A 59-year-old woman in an altered mental state, who was diagnosed as having bipolar disorder since 1988, was referred to the hospital due to impatience and aggressive behavior. As treatment with lorazepam $0.5 \mathrm{mg} /$ day, haloperidol $5 \mathrm{mg} /$ day, trazodone $25 \mathrm{mg} /$ day, and zotepine $50 \mathrm{mg} /$ day for 2 days was insufficient in controlling her symptoms of hyperactivity with grandiosity

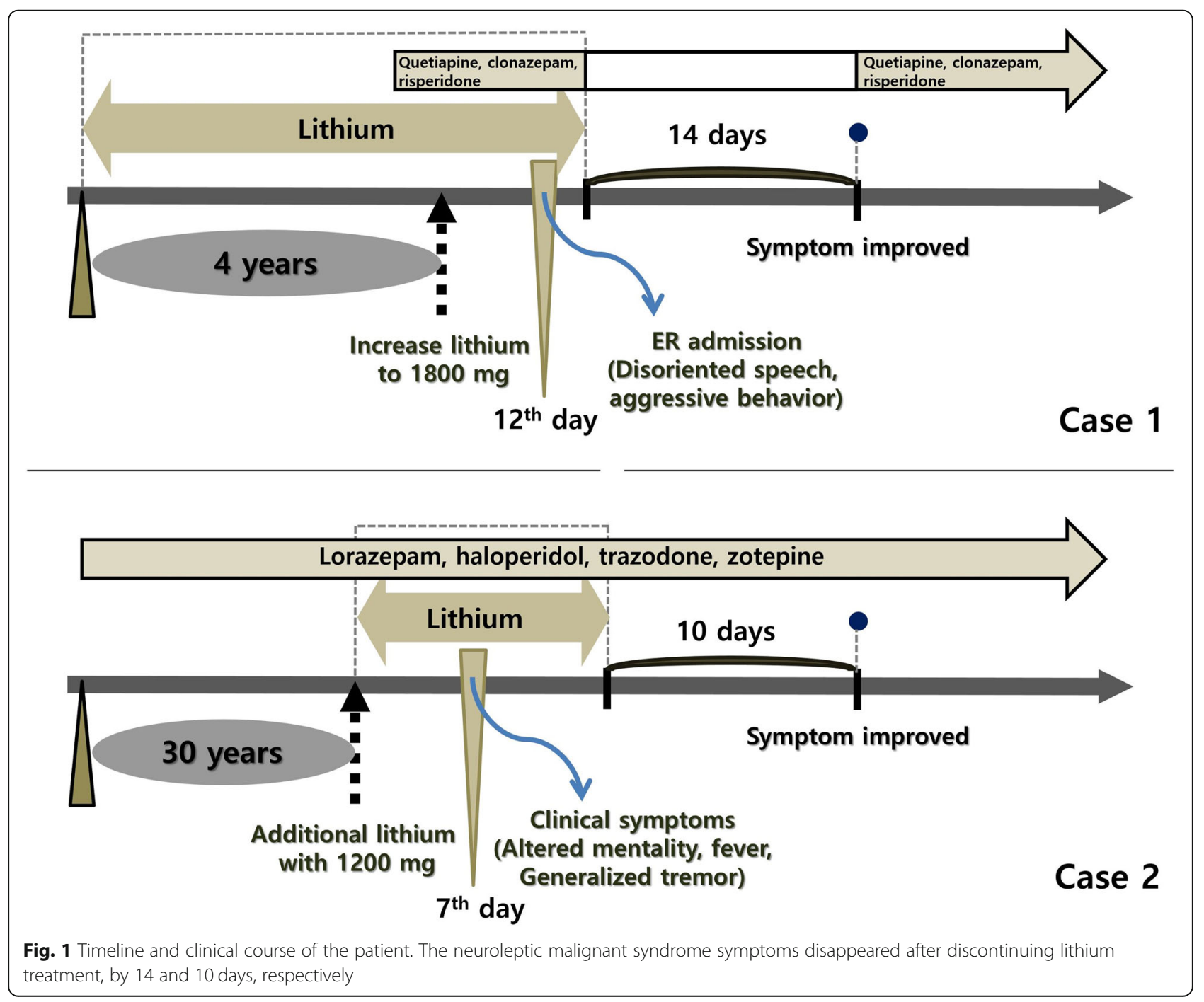




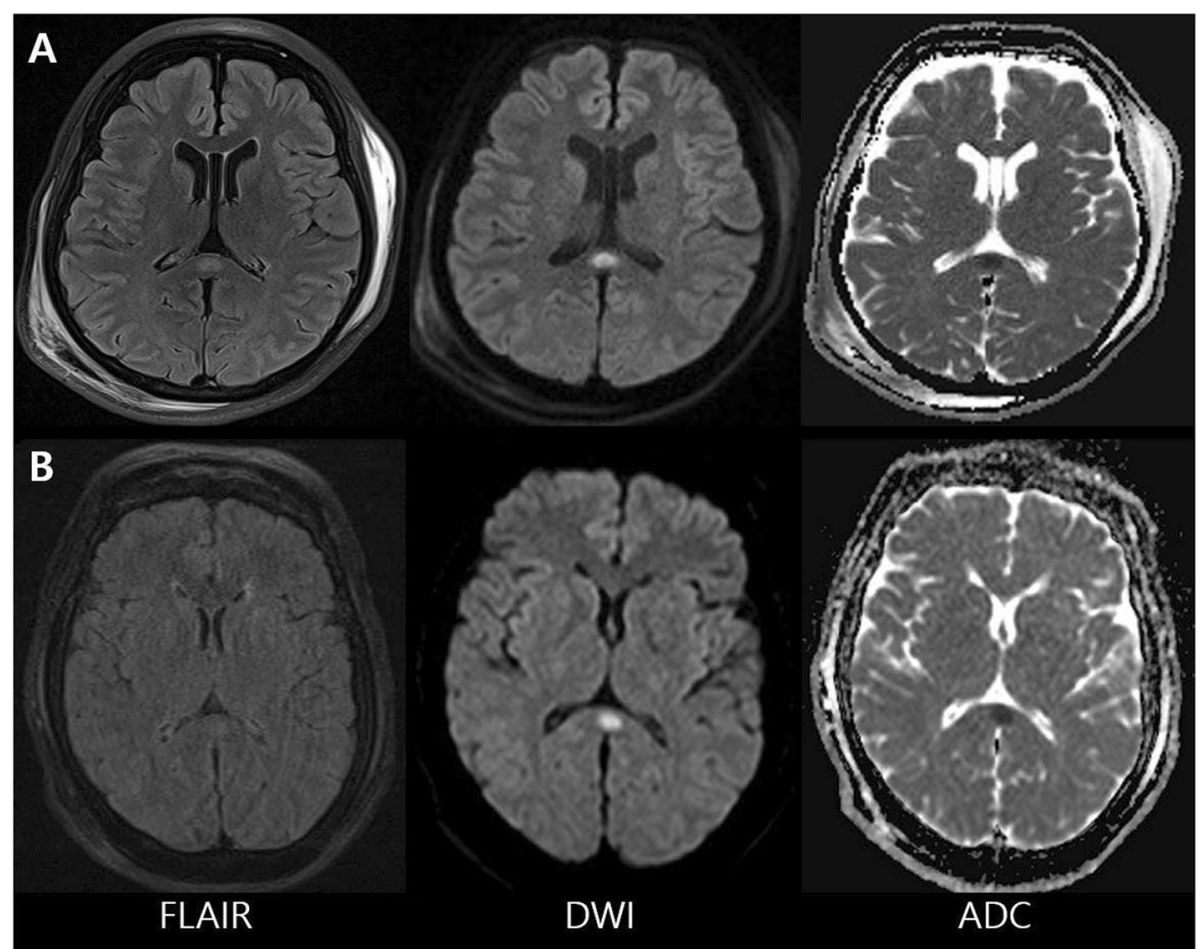

Fig. 2 Brain magnetic resonance imaging of the two patients (a, Case 1; b, Case 2). Diffusion weighted imaging in both demonstrated a high signal intensity lesion in the mid portion of the splenial corpus callosum and showed low signal intensity on the apparent diffusion coefficient map, suggestive of cytotoxic edema

and decreased need for sleep. Lithium $(1200 \mathrm{mg} /$ day) was added (Fig. 1). Two days later, her mental capacity declined. After 7 days, she developed fever $\left(38^{\circ} \mathrm{C}\right)$ and generalized tremor in both the arms and legs. Her blood pressure, heart rate, and respiration rate were 150/100 $\mathrm{mmHg}, 80$ beats/min, and 20 breaths/min, respectively. Laboratory investigations revealed mild leukocytosis but no other specific abnormal values. Her lithium level was $0.31 \mathrm{mmol} / \mathrm{L}$ and a cerebrospinal fluid study revealed no abnormalities. Brain MRI revealed swollen splenium of the corpus callosum and restriction in diffusion was observed on DWI with decreased ADC values (Fig. 2b). The patient fully recovered in 10 days after the discontinuation of lithium only.

\section{Discussion and conclusions}

As our present cases had a symptoms of NMS but does not match the diagnostic criteria of NMS exactly established by DSM-5, we described our patients as NMSLS (Table 1) [4]. The clinical presentation of RSL is nonspecific and depends on the event that may have caused the condition, such as encephalopathy or encephalitis. In a previous study, patients who showed RSL by brain MRI presented with a range of symptoms including confusion, gait ataxia, and seizure [3].
The causal mechanisms of RSL are unclear. Although the splenium has a relatively weak blood supply from the posterior pericallosal artery compared with other parts of the corpus callosum, it is unlikely that lesions are caused by ischemic injury. A previous study showed

Table 1 DSM-V Diagnostic Criteria for NMS [4]

A. Development of severe muscle rigidity and elevated temperature associated with the use of neuroleptic medication

B. Two (or more) of the following

1) Diaphoresis

2) Dysphagia

3) Tremor

4) Incontinence

6) Mutism

7) Tachycardia

8) Elevated or labile blood pressure

9) Leukocytosis

10) Laboratory evidence of muscle injury (eg, elevated creatine phosphokinase)

C. The symptoms in criteria A and B are not due to another substance or a neurological or other general medical condition

D. The symptoms in criteria A and B are not better accounted for by a mental disorder. 
that restricted diffusion imaging was reversible, with no residual lesion on follow-up with fluid attenuated inversion recovery MRI. In addition, the morphology and position of the lesion did not match those of an ischemic lesion. Several possible mechanisms have been suggested as the cause of RSL, one of which is arginine vasopressininduced disruption of body fluid homeostasis [5]. Others have proposed reversible demyelination due to infectious diseases or anti-epileptic drug toxicities. Regardless of the etiology, splenial lesion has a tendency toward a benign clinical course and reversible radiological findings on MRI. Some researchers have proposed a new clinicoradiological syndrome for RSL [6].

The suspected etiology of RSL in our cases was lithium associated neurotoxicity, which was associated with the clinical symptoms of NMSLS. In the first case, lithium had been taken for 4 years and the dose adjustment increased the level beyond the therapeutic range. We speculate that lithium intoxication played an important role in causing RSL. Despite the normal lithium level in the second case, lithium associated neurotoxicity was considered the cause of NMSLS because the clinical symptoms were concurrent with lithium treatment. Lithium associated neurotoxicity does not always correlate with serum lithium levels [7]. Interaction with other neuroleptic drugs may have increased lithium associated neurotoxicity and clinical symptoms. We suspect that lithium intoxication played a crucial role in the development of RSL as abnormal symptoms and brain MRI findings in our cases recovered after tapering lithium.

Lithium has a narrow therapeutic range, which may easily permit neurological toxicity [7]. The target dose of lithium is $0.6-1.2 \mathrm{mEq} / \mathrm{L}$ for maintenance and $1.0-1.5$ $\mathrm{mEq} / \mathrm{L}$ for manic episode control; nevertheless, neurological toxicity may be evident despite being in the therapeutic range [7]. Several cases have been reported that lithium with antipsychotics might be associated with NMS $[8,9]$. Those cases suggested that lithium toxicity can occur neurotoxic effect with NMS, but none of them showed combined lesion of RLS. To our best knowledge, there has been only one RSL case reportedly related to lithium intoxication; the serum lithium level was in the upper limit of the normal range $(0.94 \mathrm{mEq} / \mathrm{L})$ and NMSLS was not present [10]. In both of our cases, the initial splenial lesion on MRI had disappeared upon follow-up examination, suggesting cytotoxic edema. Reversible splenial lesion is reported to have a consistent pattern of neuroimaging abnormalities characterized by round lesions with hyperintense signals in fluidattenuated inversion recovery MRI and hypointense signals in T1-weighted images [11].

We experienced two cases of RSL with lithium associated neurotoxicity. Therefore, careful monitoring and evaluation of patients taking antipsychotic drugs and lithium, who show toxic neuropsychiatric symptoms, is recommended. Lithium intoxication should be considered a possible etiology of RSL with NMSLS, and this approach may help to differential diagnosis of additional workup It would be important that the NMS patients systematically get an MRI to detect RSLs, especially the patients with changes in consciousness.

\section{Abbreviations}

ADC: apparent diffusion coefficient; DWI: diffusion-weighted imaging; MRI: magnetic resonance imaging; NMSLS: neuroleptic malignant syndromelike symptoms; RSL: reversible splenial lesion

\section{Acknowledgements}

Not applicable.

\section{Authors' contributions}

HUR and HGK participated the design of this research. HUR, JYC and BSS collected and analyzed the raw clinical data. HUR, BSS, and HGK carried out computational studies and wrote the manuscript. All authors have read and approved the final manuscript.

\section{Funding}

This research was supported by "Research Base Construction Fund Support Program" funded by Jeonbuk National University, 2019. The funders had no role in study design, data collection and analysis, decision to publish, or preparation of the manuscript.

\section{Availability of data and materials}

All data and material supporting our findings are contained within the manuscript.

\section{Ethics approval and consent to participate}

Not applicable.

\section{Consent for publication}

Written informed consents were obtained from our patients for publication of this case report and any accompanying images. Our patients were able to converse with others at the moment we obtained the informed consents. A copy of the written consents are available for review by the editor of this journal.

\section{Competing interests}

HGK is a member of the editorial board (Associate Editor) of this journal. The other authors declared no conflicts of interest with respect to the research, authorship, funding, and/or publication of this article.

\section{Author details}

'Department of Neurology, Jeonbuk National University Medical School, Jeonju, South Korea. ${ }^{2}$ Department of Neurology, Chosun University School of Medicine, Gwangju, South Korea. ${ }^{3}$ Department of Neurology, Research Institute of Clinical Medicine of Jeonbuk National University - Biomedical Research Institute of Jeonbuk National University Hospital, Deokjin-gu, Jeonju-si, Jeonbuk-do 54907, South Korea.

Received: 13 January 2020 Accepted: 21 April 2020

Published online: 30 April 2020

\section{References}

1. Stern R. Lithium in the treatment of mood disorders. N Engl J Med. 1995; 332:127-8.

2. Baird-Gunning J, Lea-Henry T, Hoegberg LCG, Gosselin S, Roberts DM. Lithium poisoning. J Intensive Care Med. 2017;32:249-63.

3. Doherty MJ, Jayadev S, Watson NF, Konchada RS, Hallam DK. Clinical implications of splenium magnetic resonance imaging signal changes. Arch Neurol. 2005:62:433-7.

4. American Psychiatric Association. Diagnostic and statistical manual of mental disorders, 5th Edition (DSM-5TM). American Psychiatric Association; 2013. https://doi.org/10.1176/appi.books.9780890425596. 
5. Polster T, Hoppe M, Ebner A. Transient lesion in the splenium of the corpus callosum: three further cases in epileptic patients and a pathophysiological hypothesis. J Neurol Neurosurg Psychiatry. 2001;70:459-63.

6. Tada H, Takanashi J, Barkovich AJ, Oba H, Maeda M, Tsukahara H, et al. Clinically mild encephalitis/encephalopathy with a reversible splenial lesion. Neurology. 2004;63:1854-8.

7. Schneider JA, Mirra SS. Neuropathologic correlates of persistent neurologic deficit in lithium intoxication. Ann Neurol. 1994;36:928-31.

8. Yang Y, Guo Y, Zhang A. Neuroleptic malignant syndrome in a patient treated with lithium carbonate and haloperidol. Shanghai Arch Psychiatry. 2014;26:368-70.

9. Edokpolo O, Fyyaz M. Lithium toxicity and neurologic effects: probable neuroleptic malignant syndrome resulting from lithium toxicity. Case Rep Psychiatry. 2012;2012:271858.

10. Goto T, Ishitobi M, Takahashi T, Higashima M, Wada Y. Reversible Splenial lesion related to acute Lithium intoxication in a bipolar patient: a case report. J Clin Psychopharmacol. 2016;36:528-9.

11. Garcia-Monco JC, Cortina IE, Ferreira E, Martínez A, Ruiz L, Cabrera A, et al. Reversible splenial lesion syndrome (RESLES): what's in a name? J Neuroimaging. 2011;21:e1-14.

\section{Publisher's Note}

Springer Nature remains neutral with regard to jurisdictional claims in published maps and institutional affiliations.

Ready to submit your research? Choose BMC and benefit from:

- fast, convenient online submission

- thorough peer review by experienced researchers in your field

- rapid publication on acceptance

- support for research data, including large and complex data types

- gold Open Access which fosters wider collaboration and increased citations

- maximum visibility for your research: over $100 \mathrm{M}$ website views per year

At BMC, research is always in progress.

Learn more biomedcentral.com/submissions 